\title{
Kjenn tegnene på delirium hos eldre
}

Hvis sykepleierne kjenner tegnene på delirium hos eldre pasienter på hjerteavdelingen, kan de lettere forebygge og behandle tilstanden.

\section{Leslie S.P. Eide}

Førsteamanuensis

Høgskulen på Vestlandet

\section{Irene Instenes}

Spesialsykepleier i geriatri

Hjerteavdelingen, Haukeland universitetssjukehus

\section{Anette H. Ranhoff}

Professor i geriatri

Universitetet i Bergen, Kavli forskningssenter for geriatri og demens, Diakonhjemmet sykehus og Haraldsplass Diakonale Sykehus

\section{Hege Andersen Amofah}

Spesialsykepleier i geriatri

Haukeland universitetssjukehus

\section{Tone Merete Norekvål}

Fag- og forskningssykepleier og professor

Hjerteavdelingen, Haukeland universitetssjukehus, Universitetet i Bergen og Høgskulen på Vestlandet

\section{Delirium Hjerte- og karsykdom Eldre}

\section{Hovedbudskap}


Stadig flere eldre får tilbud om avansert hjertebehandling. Sykepleiere på hjerteavdelingen vil $m \varnothing t$ te flere eldre pasienter med delirium. Forskning viser at ikke-farmakologiske intervensjoner gir de beste resultatene når tilstanden forebygges og behandles. Artikkelen drøfter risikofaktorer og forebyggende tiltak ved delirium hos eldre pasienter innlagt på hjerteavdelingen og gir eksempler på hvordan pasienter opplever å ha delirium.

Delirium er en tilstand som karakteriseres ved akutte forandringer i kognitiv funksjon, oppmerksomhet og bevissthet som følge av en eller flere fysiologiske påkjenninger $(1,2)$. Forandringene kan variere i intensitet i løpet av døgnet og avviker fra hvordan pasienten er til vanlig (1). De fleste sykepleiere har erfaring med deliriske pasienter, og mange vil assosiere delirium med agiterte eller utagerende personer som prøver å fjerne urinkateter, dren og medisinsk utstyr. Få vet derimot at pasienter som sover usedvanlig mye, har problemer med å følge instruksjoner, svarer kort på tiltale eller sovner under samtalen, også kan ha delirium (3).

Pasienthistorie 1: Kvinne 86 år beskriver sin opplevelse av delirium postoperativt etter aortaklaffkirurgi:

«Jeg husker en natt spesielt, jeg var inne i en masse klær. Klarte ikke å finne veien ut igjen. Det var en sånn merkelig tilstand ... du drømte, men likevel så var du lys våken.» (4)

Mangelfull kunnskap om delirium kan føre til feilvurderinger og redusert pasientsikkerhet. I vår kliniske hverdag kommer vi i kontakt med pasienter som kan feilvurderes til å ha demens eller psykiatrisk sykdom, men som i realiteten har delirium. Forskning viser at delirium etter hjerteprosedyrer er knyttet til lengre sykehusopphold (5), høyere risiko for reinnleggelser (6), redusert fysisk funksjon $(7,8)$ og kognitiv dysfunksjon (9). Delirium medfører behov for videre oppfølging i institusjon og $\varnothing$ kte behandlingskostnader (10) samt høyere dødelighet $(6,11)$.

Det er ikke uvanlig at pasienter som ikke har symptomer på delirium når de legges inn på sykehus, utvikler delirium under oppholdet. I takt med at flere eldre får tilbud om avansert hjertemedisinsk og kirurgisk behandling, kan det forventes at delirium blir et $\varnothing$ kende problem ved hjerteavdelingen. 
Sykepleierrollen endres med nye utfordringer da sykepleieren ofte er i tettere kontakt med disse pasientene enn annet helsepersonell (12). Flere av de ikkefarmakologiske strategiene som har vist seg å være effektive ved forebygging av delirium (13, 14), er også en naturlig del av sykepleierens oppgaver. Denne artikkelen har derfor som hensikt å drøfte risikofaktorer og forebyggende tiltak ved delirium hos eldre pasienter innlagt på hjerteavdelingen.

\section{Patofysiologi og risiko}

Patofysiologien ved delirium er ikke tilstrekkelig kartlagt, men det er kjent at en kombinasjon av predisponerende og utløsende faktorer kan føre til delirium (15). Predisponerende faktorer er karakteristika ved pasienten som ikke lar seg påvirke, slik som alder $\geq 75$ år, kognitiv svikt, komorbiditet eller tidligere gjennomgått delirium $(15,16)$. Delirium kan utløses av direkte påvirkning på hjernen, som for eksempel et hjerneslag. De vanligste utløsende faktorene er imidlertid ubalanse i kroppen som hypoksi, inflammasjon og metabolske forstyrrelser i blodsukker eller elektrolytter.

Aldersforandringer fører til redusert reservekapasitet i mange organer med sårbarhet for organsvikt. Videre fører de til redusert homeostase og reduserte kompensasjonsmekanismer. Faktorer som er mindre vesentlige for yngre og robuste individer, som for eksempel urinveisinfeksjon, stress, høreapparat eller briller som ikke blir benyttet, kan bidra til delirium hos eldre pasienter (17). I en hjerteavdeling kan smerte, enten etter hjerteprosedyrer eller ved angina, hypoksi, bruk av monitoreringsutstyr og redusert søvnkvalitet, være utløsende faktor for delirium.

Ulike typer inngrep, inkludert aortaklaffkirurgi, har også blitt identifisert som utløsende faktorer for delirium hos pasienter over 80 år (18). Figur 1 viser predisponerende og utløsende faktorer for utvikling av delirium hos hjertepasienter. 


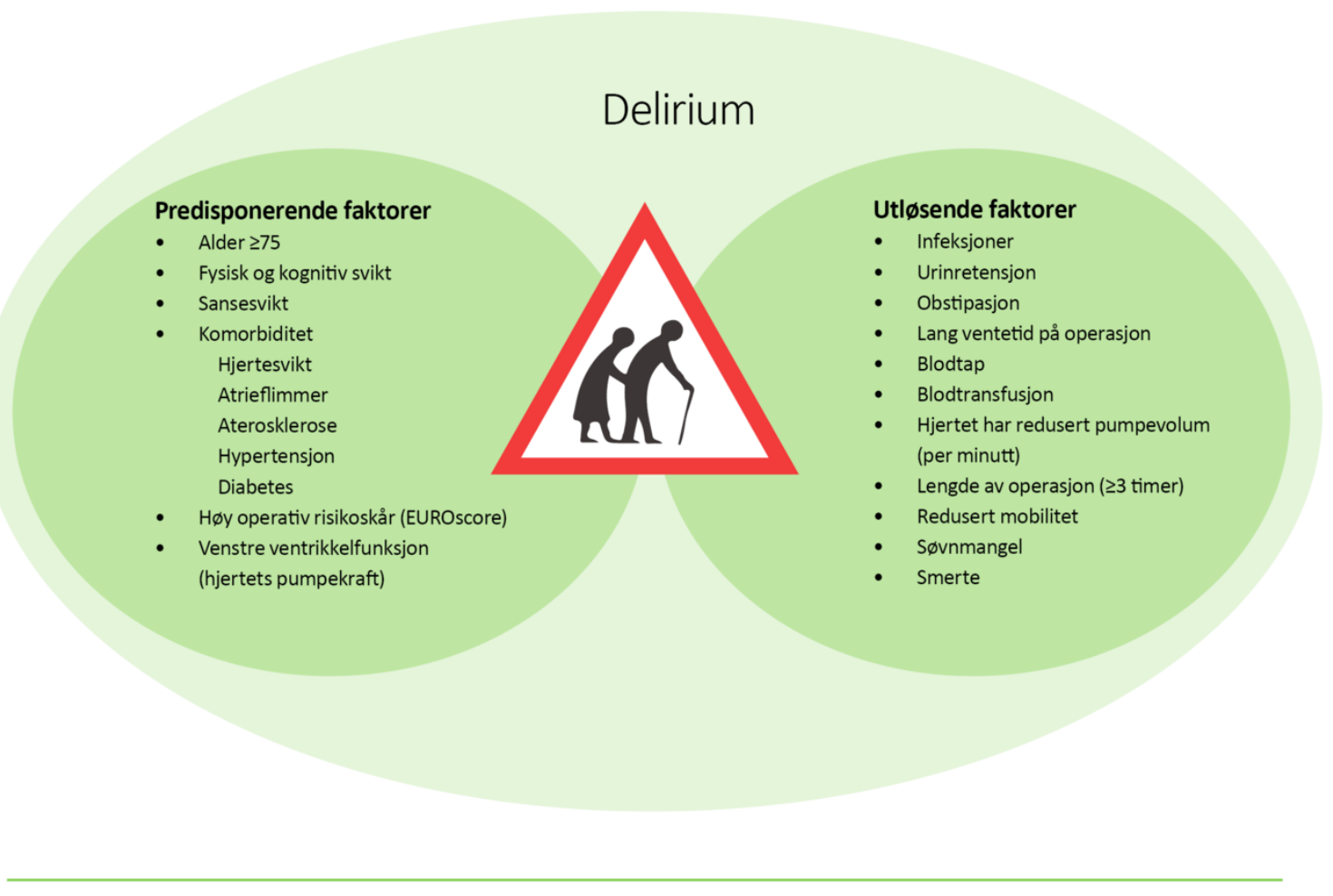

\section{Kan også være rolige}

Med utgangspunkt i psykomotorisk aktivitet kan delirium klassifiseres som hyperaktiv, hypoaktiv eller blandet (19). Ved hjerteavdelingen kan hyperaktivt delirium identifiseres ved at pasienten er urolig og har problemer med å forstå at medisinsk-teknisk utstyr er nødvendig. Pasienten kan forsøke å fjerne monitorledninger, oksygenmaske, urinkateter eller veneflon samt klatre over sengehesten. Pasienter med hypoaktivt delirium kan virke fjerne og apatiske. Forandringene i oppmerksomhet og bevissthet fører til at de har vanskeligheter med å holde seg våkne under samtaler. De kan også ha problemer med å følge instruksjoner fra fysioterapeut og annet personell.

\section{«For pasienter med delirium er forstyrret oppmerksomhet og bevissthet karakteristiske symptomer.»}

For pasienter med delirium er forstyrret oppmerksomhet og bevissthet karakteristiske symptomer (1). Pasientene kan ha vanskeligheter med å følge instruksjoner, eller de fremviser unormal motorisk aktivitet som varierer i intensitet i løpet av døgnet. Dessuten kan pasienter med delirium ha kognitive forstyrrelser i form av redusert hukommelse, desorientering eller persepsjonsforstyrrelser (1) (tabell 1). 
A Forstyrret oppmerksomhet (for eksempel redusert evne til å fokusere, opprettholde og/eller endre oppmerksomhet) og bevissthet (redusert evne til å orientere seg i omgivelsene).

B Forstyrrelsene utvikler seg i løpet av kort tid (vanligvis timer til noen få dager), representerer en akutt endring fra vanlig oppmerksomhet og bevissthet, og har tendens til å fluktuere i grad av alvorlighet gjennom døgnet.

C Ytterligere forstyrret kognisjon (for eksempel redusert hukommelse, desorientering, språk- eller persepsjonsforstyrrelser).

D Forstyrrelsene i kriteriene A og C blir ikke bedre forklart av en allerede kjent nevrokognitiv lidelse eller oppvåkningsfasen fra koma.

E Det er holdepunkter fra sykehistorie, klinisk unders $\varnothing$ kelse eller laboratoriesvar for at forstyrrelsen er en direkte fysiologisk konsekvens av en annen medisinsk tilstand, forgiftning av kjemiske substanser (rusmidler eller legemidler), abstinens, annen toksisk påvirkning eller har multiple årsaker.

Hentet fra det amerikanske psykiatriske diagnosesystemet Diagnostic and Statistic Manual 5 (DSM-5) (31).

Pasienthistorie 2: Kvinne 88 år beskriver hallusinasjoner i delirium postoperativt etter aortaklaffkirurgi:

«Det gikk et sånt rør oppi taket og der krøp det dyr bortetter. Så ble det verre, hele veggen kom imot meg. Det var fryktelig ubehagelig. Jeg skrek slik at jeg ikke fikk komme inn på sykepleiernes vaktrom.» (4)

Det er viktig å påpeke at delirium ikke er en sykdom i seg selv, men et tegn på akutt hjernesvikt og ubalanse som kroppen ikke klarer å kompensere for. For eldre pasienter kan selve hjerteintervensjonen og de nødvendige prosedyrene relatert til denne, være utløsende faktorer for tilstanden. Dette kan være elektroder og ledninger som overvåker hjertefunksjonen, urinkateter, immobilitet, forflytting fra intensiv til sengepost, dehydrering eller bruk av sedativer. Komplikasjoner som blødning, infeksjoner eller atrieflimmer kan også være utløsende faktorer for tilstanden (figur 1).

\section{Identifisere delirium}

Pasienten kan veksle mellom å ha hypo- og hyperaktivt delirium i løpet av kort tid, og disse variasjonene gjør det vanskelig å identifisere delirium. I tillegg kan akutte forandringer i oppmerksomhet, bevissthet og kognitiv funksjon være vanskelige å oppdage, spesielt for pasienter som er akutt innlagt. Pårørende er ofte de første som oppdager forandringene, og deres innspill er derfor viktige. 
Det er utviklet flere instrumenter som brukes til å identifisere delirium. The Confusion Assessment Method (CAM) (20) er det mest kjente (21, 22). CAM vurderer om det har oppstått forstyrrelser i oppmerksomhet og bevissthet i løpet av kort tid, det vil si timer eller noen få dager. Instrumentet vurderer i tillegg om disse forstyrrelsene representerer en akutt endring i tilstanden. CAM identifiserer om pasienten har en desorganisert tankegang, og om denne veksler $\mathrm{i}$ alvorlighetsgrad gjennom døgnet. CAM er oversatt til norsk (23) og har blitt validert for pasienter etter hjertekirurgi (24). 4AT (25) er et nytt instrument til å identifisere delirium, som er enkelt i bruk og oversatt til norsk (26).

\section{Forebyggende tiltak}

Sykepleieren har en viktig rolle for å forebygge delirium da flere av de utløsende faktorene ved delirium er tett relatert til sykepleiefaglige oppgaver. Det kan være utfordrende å skulle ivareta pasienter med delirium, en situasjon som både er ressurs- og tidkrevende i en hektisk sykehushverdag. Sykepleieren er ofte den første som registrerer endring i pasientens mentale tilstand, og som er ansvarlig for videre oppfølging og behandling. Dagens hjerteavdelinger er sammensatte, og pasienter i ulik alder med svært forskjellig behandlingsbehov ivaretas på samme enhet. Eldre pasienter utsettes ofte for stress, støy og tidsknapphet - faktorer som påvirker utvikling av delirium på en negativ måte (12).

\section{«Sykepleieren har en viktig rolle for å forebygge delirium da flere av de utløsende faktorene ved delirium er tett relatert til sykepleiefaglige oppgaver.»}

Pasienthistorie 3: Kvinne 82 år beskriver hvordan hun i delirium klarte å orientere seg ved hjelp av omgivelsene utenfor sykehusvinduet:

«Jeg så ut av vinduet og så dette fjellet. Jeg husker at utsikten forvirret meg. Plutselig forsto jeg hvilket fjell det var og klarte ved hjelp av dette å finne ut hvilket sykehus jeg befant meg på.» (4)

Forskning har vist at det er mulig å forebygge en tredjedel av alle tilfeller av delirium. Pasienter med høy risiko for å utvikle delirium må vies ekstra oppmerksomhet (16). Nylig publiserte data viser hvordan pasienter over 80 år opplevde forstyrrelser i $\emptyset$ vn-, hvile- og aktivitetsmønster postoperativt.

I denne studien utførte vi både subjektive og objektive målinger av søvn i fem postoperative dager. Det fremgår tydelig av resultatene hvordan pasientene opplevde redusert og avbrutt søvn etter både aortaklaffkirurgi (SAVR) og kateterbasert aortaklaffimplantasjon (TAVI). I tillegg sov pasientene mer på dagtid enn om natten, noe som igjen førte til inaktivitet (27). 


\section{Behandle delirium}

Behandling av delirium inneholder hovedsakelig to komponenter: behandling av underliggende årsak(er) og tilrettelegging av miljøet rundt pasienten. Med kartlegging og behandling av de antatt akutt underliggende årsakene mener vi for eksempel å sikre adekvat oksygeninnhold i blodet, tilfredsstillende ernæring og væskebalanse samt normale naturlige funksjoner som tarm- og blærefunksjon (16). Videre bør utløsende faktorer ivaretas, som medisinering, smertelindring, infeksjoner og søvnforstyrrelser (28).

Den andre komponenten er å tilrettelegge miljøet rundt pasienten (16). Pasientens evne til orientering fremmes ved å tilstrebe tilstrekkelig nattes $\varnothing \mathrm{vn}$, rolige og oversiktlige omgivelser samt lett synlig kalender og klokke i pasientrommet. I tillegg må sansesvikt korrigeres med velfungerende briller og høreapparat (29). Kommunikasjon og informasjon er viktig når delirium skal behandles (29). Det å snakke med pasienten om årsaken til sykehusinnleggelsen og hvilken rolle du som sykepleier har, er bedre enn å spørre vedkommende om han vet hvor han er, eller hvem du er.

\section{«Trygghet er et nøkkelord i arbeidet med pasienter med delirium.»}

Trygghet er et nøkkelord i arbeidet med pasienter med delirium. Dersom det er mulig at pasienten får enerom, og at pårørende kan være mest mulig til stede, kan det bidra til å $\varnothing$ ke tryggheten til pasienter med delirium. Likevel har noen pasienter behov for fastvakt. Mobilisering er også et tiltak i behandling av delirium (30).

Vår kliniske erfaring viser at det er mulig å mobilisere pasienter på eller over 80 år tidlig etter hjertekirurgi. For en nylig hjerteoperert pasient kan det å sitte oppe i en stol bidra til å øke oksygenering og perfusjon, og det kan forbedre orienteringen (23). Likevel kan mobilitet bli påvirket av medisinsk-teknisk utstyr og bruk av urinkateter. Bruk av permanent urinkateter må derfor vurderes nøye og seponeres så fort det er forsvarlig.

I noen tilfeller kan det være aktuelt å benytte farmakologisk behandling. Dette gjelder særlig pasienter som opplever hallusinasjoner, er utagerende og representerer en fare for seg selv og andre. Lavdosenevroleptika (haloperidol) kan brukes for å korrigere en slik uønsket endring i persepsjon og atferd. Antipsykotisk behandling (olanzapin, risperidon) er fors $\varnothing \mathrm{kt}$ som behandling, men det finnes ikke tilstrekkelig evidens som viser at legemidler reduserer symptomer, omfang eller lengden av deliriumstilstanden. Imidlertid må det tas i betraktning at bruk av antipsykotiske legemidler kan forlenge et delirium og har vist å forverre kognitiv og fysisk funksjonssvikt hos pasienter med Alzheimer (16). 


\section{Oppsummering}

Delirium er en tilstand karakterisert ved akutt forandring og fluktuerende endringer av mental funksjon med uoppmerksomhet og endret bevissthetsnivå. Ettersom flere eldre pasienter får tilbud om avansert hjertebehandling, er det viktig at sykepleiere kjenner til predisponerende og utløsende faktorer for delirium, slik at pasienter som er i risikosonen, kan identifiseres og behandles. Kjennskap til de ulike formene for delirium - hyperaktiv, hypoaktiv og blandet - kan bidra til å optimalisere pleien som sykepleiere utøver.

\section{Referanser}

1. European Delirium Association, American Delirium Society. The DSM-5 criteria, level of arousal and delirium diagnosis: inclusiveness is safer. BMC Med 2014;12:141.

2. Lauck SB, Kwon JY, Wood DA et al. Avoidance of urinary catheterization to minimize in-hospital complications after transcatheter aortic valve implantation: An observational study. Eur J Cardiovasc Nurs 2017:1474515117716590. DOI: 10.1177/1474515117716590. 27.06.2017.

3. Inouye SK, Foreman MD, Mion LC, Katz KH, Cooney LM Jr. Nurses' recognition of delirium and its symptoms: comparison of nurse and researcher ratings. Arch Intern Med 2001;161(20):2467-73.

4. Instenes I, Gjengedal E, Eide LS, Kuiper KK, Ranhoff AH, Norekval TM. «Eight days of nightmares ...... »- Octogenarian patients' experiences of postoperative delirium after Transcatheter or Surgical Aortic Valve Replacement. Heart Lung Circ 2017. DOI: 10.1016/j.hlc.2017.02.012.12.04.2017.

5. Mangusan RF, Hooper V, Denslow SA, Travis L. Outcomes associated with postoperative delirium after cardiac surgery. Am J Crit Care 2015;24(2):156-63.

6. Eide LS, Ranhoff AH, Fridlund B, Haaverstad R, Hufthammer KO, Kuiper KK et al. Readmissions and mortality in delirious versus non-delirious octogenarian patients after aortic valve therapy: a prospective cohort study. BMJ Open 2016;6(10):e012683.

7. $\quad$ Eide LS, Ranhoff AH, Fridlund B, Haaverstad R, Hufthammer KO, Kuiper KK et al. Delirium as a predictor of physical and cognitive function in individuals aged 80 and older after Transcatheter Aortic Valve Implantation or Surgical Aortic Valve Replacement. J Am Geriatr Soc 2016;64(6):1178-86. 
8. Koster S, Hensens AG, Schuurmans MJ, van der Palen J. Consequences of delirium after cardiac operations. The Annals of Thoracic Surgery 2012;93(3):70511.

9. Saczynski JS, Marcantonio ER, Quach L, Fong TG, Gross A, Inouye SK et al. Cognitive trajectories after postoperative delirium. N Engl J Med 2012;367(1):30-9.

10. Rudolph JL, Boustani M, Kamholz B, Shaughnessey M, Shay K, American Delirium Society. Delirium: a strategic plan to bring an ancient disease into the 21st century. J Am Geriatr Soc 2011;59 Suppl 2:S237-40.

11. Pauley E, Lishmanov A, Schumann S, Gala GJ, van Diepen S, Katz JN. Delirium is a robust predictor of morbidity and mortality among critically ill patients treated in the cardiac intensive care unit. Am Heart J 2015;170(1):79-86, e1.

12. Dahlke S, Phinney A. Caring for hospitalized older adults at risk for delirium: the silent, unspoken piece of nursing practice. J Gerontol Nurs 2008;34(6):41-7.

13. Hshieh TT, Yue J, Oh E, Puelle M, Dowal S, Travison T et al. Effectiveness of multicomponent nonpharmacological delirium interventions: a meta-analysis. JAMA Intern Med 2015;175(4):512-20.

14. Siddiqi N, Harrison JK, Clegg A, Teale EA, Young J, Taylor J et al. Interventions for preventing delirium in hospitalised non-ICU patients. Cochrane Database Syst Rev. 2016;3:CDoo5563.

15. Inouye SK, Westendorp RG, SaczynskiSaczynski JS. Delirium in elderly people. Lancet. 2014;383(9920):911-22.

16. Kukreja D, Gunther U, Popp J. Delirium in the elderly: Current problems with increasing geriatric age. Indian J Med Res 2015;142(6):655-62.

17. Maclullich AM, Ferguson KJ, Miller T, de Rooij SE, Cunningham C. Unravelling the pathophysiology of delirium: a focus on the role of aberrant stress responses. J Psychosom Res 2008;65(3):229-38.

18. Eide LS, Ranhoff AH, Fridlund B, Haaverstad R, Hufthammer KO, Kuiper KK et al. Comparison of frequency, risk factors, and time course of postoperative delirium in octogenarians after transcatheter aortic valve implantation versus surgical aorticaortic valve replacement. Am J Cardiol 2015;115(6):802-9.

19. Lipowski ZJ. Delirium updated. Compr Psychiatry 1980;21(3):190-6. 
20. Inouye SK, van Dyck CH, Alessi CA, Balkin S, Siegal AP, Horwitz RI. Clarifying confusion: the confusion assessment method. A new method for detection of delirium. Ann Intern Med 1990;113(12):941-8.

21. van Velthuijsen EL, Zwakhalen SM, Warnier RM, Mulder WJ, Verhey FR, Kempen GI. Psychometric properties and feasibility of instruments for the detection of delirium in older hospitalized patients: a systematic review. Int $\mathrm{J}$ Geriatr Psychiatry 2016;31(9):974-89.

22. Wong CL, Holroyd-Leduc J, Simel DL, Straus SE. Does this patient have delirium?: value of bedside instruments. JAMA 2010;304(7):779-86.

23. Ranhoff AH. Delirium (akutt forvirring) I: Kirkevold M, Brodtkorb K, Ranhoff AH (red.). Geriatrisk sykepleie: God omsorg til den gamle pasienten. Oslo: Gyldendal Akademisk; 2015. s. 452-62.

24. Smulter N, Lingehall HC, Gustafson Y, Olofsson B, Engstrom KG. Validation of the Confusion Assessment Method in detecting postoperative delirium in cardiac surgery patients. Am J Crit Care 2015;24(6):480-7.

25. MacLullich AM. 4AT - Rapid assessment test for delirium 2011. Tilgjengelig fra: http://www.the4at.com/ (nedlastet 23.02.2017).

26. Evensen S, Forr T, Al-Fattal A, de Groot C, Lønne G, Gjevjon E et al. Nytt verktøy for å oppdage delirium og kognitiv svikt. Tidsskr Nor Legeforen 2016(136):299-300.

27. Amofah HA, Brostrom A, Fridlund B, Bjorvatn B, Haaverstad R, Hufthammer $\mathrm{KO}$ et al. Sleep in octogenarians during the postoperative phase after transcatheter or surgical aortic valve replacement. Eur J Cardiovasc Nurs 2016;15(2):168-77.

28. Irwin SA, Pirrello RD, Hirst JM, Buckholz GT, Ferris FD. Clarifying delirium management: practical, evidenced-based, expert recommendations for clinical practice. J Palliat Med 2013;16(4):423-35.

29. Delirium: Diagnosis, prevention and management. London: National Clinical Guideline Centre - Acute and Chronic Conditions; juli 2010.

30. Nydahl P, Sricharoenchai T, Chandra S, Kundt FS, Huang M, Fischill M et al. Safety of patient mobilization and rehabilitation in the ICU: Systematic review with meta-analysis. Ann Am Thorac Soc 2017;14(5):766-77. 
31. American Psychiatric Association. Diagnostic and statistical manual of mental disorders. Virginia, USA: American Psychiatric Association; 2014.

32. Arora RC, Djaiani G, Rudolph JL. Detection, prevention, and management of delirium in the critically ill cardiac patient and patients who undergo cardiac procedures. Can J Cardiol 2017;33(1):80-7.

33. Hollinger A, Siegemund M, Goettel N, Steiner LA. Postoperative delirium in cardiac surgery: An unavoidable menace? J Cardiothorac Vasc Anesth 2015;29(6):1677-87.

34. Koster S, Hensens AG, Schuurmans MJ, van der Palen J. Risk factors of delirium after cardiac surgery: A systematic review. Eur J Cardiovasc Nurs 2011;10(4):197-204. 